\title{
Article \\ Thixotropic Behavior in Defining Particle Packing Density of Highly Filled AP/HTPB-Based Propellant
}

\author{
Afni Restasari *, Luthfia Hajar Abdillah, Retno Ardianingsih, Hamonangan Rekso Diputro Sitompul (D), \\ Rika Suwana Budi, Kendra Hartaya and Heri Budi Wibowo
}

Citation: Restasari, A.; Abdillah, L.H.; Ardianingsih, R.; Sitompul, H.R.D.; Budi, R.S.; Hartaya, K.; Wibowo, H.B. Thixotropic Behavior in Defining Particle Packing Density of Highly Filled AP/HTPB-Based Propellant. Symmetry 2021, 13, 1767. https://doi.org/10.3390/ sym13101767

Academic Editors: Adam Glowacz, Muhammad Irfan,

Wahyu Caesarendra and Hui Liu

Received: 24 August 2021

Accepted: 18 September 2021

Published: 23 September 2021

Publisher's Note: MDPI stays neutral with regard to jurisdictional claims in published maps and institutional affiliations.

Copyright: (c) 2021 by the authors. Licensee MDPI, Basel, Switzerland. This article is an open access article distributed under the terms and conditions of the Creative Commons Attribution (CC BY) license (https:// creativecommons.org/licenses/by/ $4.0 /)$.
Research Organization of Aeronautics and Space, National Agency for Research and Innovation, Jakarta 13220, Indonesia; luthfia.hajar@lapan.go.id (L.H.A.); retno.ardianingsih@lapan.go.id (R.A.); hamonangan.rsitompul@lapan.go.id (H.R.D.S.); rika.suwana@lapan.go.id (R.S.B.); kendra.hartaya@lapan.go.id (K.H.); heri.budi@lapan.go.id (H.B.W.)

* Correspondence: afni.restasari@lapan.go.id

\begin{abstract}
An alarming, asymmetric flame in rocket combustion originates from a composite solid propellant (CSP) containing defects. The defects are the result of a composition that exceeds the maximum particle packing density. Based on the structure analysis of CSP, the addition of plasticizer causes the correlation between the viscosity of CSP slurry and particle packing density to become uncertain. This work aims to investigate the influence of thixotropic behavior on the maximum particle packing density of CSP. A CSP with different thixotropic behavior was successfully produced using aluminum/ plasticizer dioctyl adipate (DOA) of 12-24. During the curing process, viscosity and stress-growth were investigated. The structure of the CSP was defined using X-ray radiography. It is remarkably observed that the peak of thixotropy occurred at the 15th minute of the curing process. The particle packing density of CSP can be decisive for the relative viscosity at the peak time of thixotropic behavior. The CSP with the highest relative viscosity at the peak time was revealed to have voids in the upper part of the CSP. Thus, this parameter was proven to change the preceding parameter, viscosity that was measured at the end of mixing. Based on the stress-growth analysis, it is conceivable that the mechanism involves the time-dependent diffusion of DOA in weakening aluminum agglomerates.
\end{abstract}

Keywords: rheology; highly filled polymer; deformation; thixotropy; agglomeration; plasticizer; particle packing; defects; propellant; stress

\section{Introduction}

Composite solid propellant (CSP) is the major component in many propulsion systems. It is commonly adopted for sounding rockets, space launch boosters, and jets. Recently, CSP has been used to support space exploration, particularly AP/HTPB-based CSP, which is also the most widely used propellant [1,2]. CSP has several advantages over liquid propellants, including easy manufacture, storage stability, resistance to inadvertent detonation, and chemical stability [3]. As a composite material, AP/HTPB-based CSP consists of solid content (SC) embedded in a polymeric matrix. The matrix is a result of polymerization between a polyol such as hydroxyl-terminated polybutadiene (HTPB) and curing agents, such as isocyanate compounds. The SC includes inorganic oxidizers, ammonium perchlorate (AP), and metallic fuels such as aluminum [4]. The composition of the CSP has a significant impact on its performance. In most cases, 70-80\% of SC is applied. A high amount of solid content is necessary to generate immense energy, such as $88 \%$ solid content with 25\% aluminum [3,5]; this complicates the manufacture of CSP. As previously stated, AP/HTPB-based CSP with $85 \%$ SC and 18\% aluminum cannot be cast easily [6].

The production of AP/HTPB-based CSP includes mixing and casting processes. There are two steps in the mixing procedure: 
1. The HTPB liquid is mixed with the solid content in the first step to create a concentrated suspension known as CSP slurry. In this case, HTPB has a tribological effect. It penetrates particle gaps and forms a layer on the surface of the particles. It lowers particle friction, allowing particles to be freely mixed and well dispersed throughout the HTPB $[7,8]$.

2. An isocyanate molecule is introduced in the second step. It starts a polymerization reaction with HTPB to produce polyurethane, a polymeric matrix. The process causes the viscosity of the CSP slurry to increase over time. The duration of the second step is less than that of the first to obtain the appropriate viscosity value for casting [8].

According to reports, the optimum viscosity for vacuum casting is less than 16,000 Poise, while for pressure casting is less than 50,000 Poise [9]. The casting process becomes complicated if the viscosity of the AP/HTPB-based CSP slurry exceeds the viscosity limit, resulting in defects in the structure of CSP solids such as voids, porosity, voids with tails, craze, and cracks. As a result, the asymmetric combustion of CSP occurs, causing damage to the rocket motor $[10,11]$. Figure 1 shows examples of CSP solids with voids, detected using an X-ray. Figure 2 depicts a rocket motor that has been harmed by asymmetric combustion. To avoid damages, plasticizer compound is added.

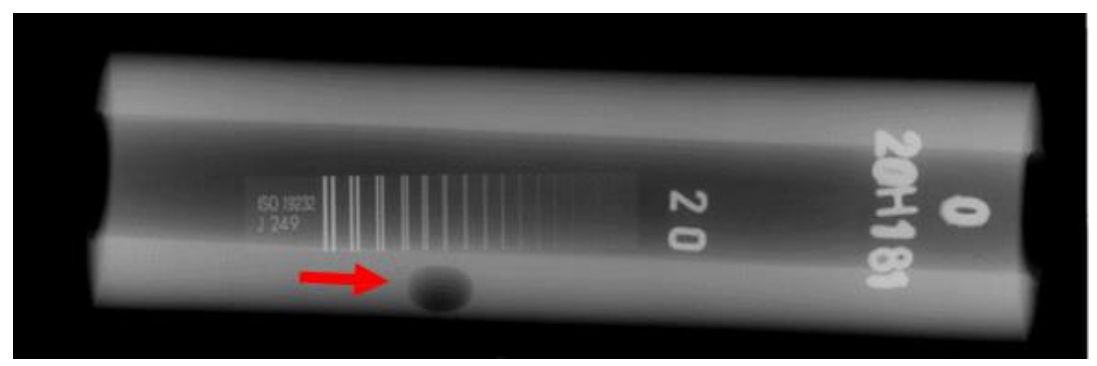

Figure 1. An example of a structural flaw in CSP. The magnitude of a void indicated by a red arrow is un-neglectable.

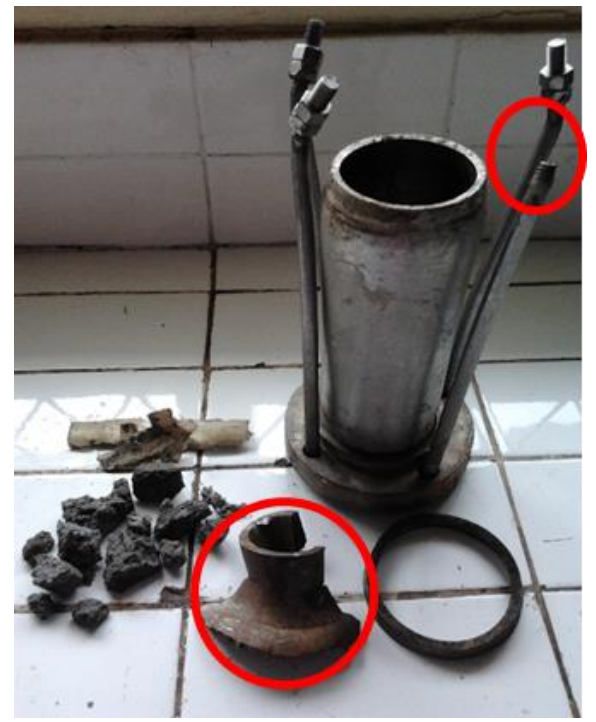

Figure 2. An example of a damaged motor of a rocket produced by an asymmetrical flame generated by a flawed structure of CSP.

Dioctyl adipate (DOA) is a widely used plasticizer for AP/HTPB-based CSP. It is preferred because it has a similar value of Hansen Solubility Parameter (HSP) (17.6 $\mathrm{MPa}^{0.5}$ ) to HTPB [12]. Because of these similarities, HTPB and DOA are compatible, and DOA's chain is effective in lubricating HTPB's swarming chain. It reduces the viscosity of HTPB [12-14]; it has been found that adding 20\% DOA to HTPB reduces the viscosity of HTPB by 
50-62.5\%. Meanwhile, for HTPB-TDI, it reduces by $88 \%$ [15-17]. When used in CSP, adding 3\% DOA reduces the viscosity of the slurry by up to $55 \%$ [18]. Adding DOA to the CSP slurry is also a simple technique used to modify the viscosity for different applications. For example, a larger rocket booster needs a more dilute CSP slurry. However, despite all of the benefits, it has been observed that improper DOA addition might cause structural damage [19]. It contrasts the particle packing concept of which only CSP with a SC greater than the maximum particle packing density, as indicated by high viscosity, would be damaged $[7,20,21]$. Since it has a low viscosity, the DOA-contained CSP slurry should be distant from maximum particle packing density. As a result of this occurrence, it is possible that the parameters for determining the particle packing density change (Table 1).

Table 1. Several models that correlate viscosity ratio $\left(\eta_{\mathrm{r}}=\eta_{\text {slurry }} / \eta_{\text {binder }}\right)$ and packing fraction $\left(P F=\phi / \phi_{\mathrm{m}}\right)[19]$.

\begin{tabular}{ll}
\hline \multicolumn{1}{c}{ Authors } & \multicolumn{1}{c}{ Model } \\
\hline Eilers (1941) [22] & $\eta_{\mathrm{r}}=\left(1+\frac{1.25 \varphi}{1-P F}\right)^{2}$ \\
\hline Mooney (1951) [23] & $\operatorname{Ln}\left(\eta_{\mathrm{r}}\right)=\left(\frac{k \varphi}{1-P F}\right)$ \\
\hline Krieger and Dougherty (1959) [24] & $\eta_{\mathrm{r}}=(1-P F)^{-[\eta] \phi m}$ \\
\hline Chong (1971) [25] & $\eta_{\mathrm{r}}=\left(1+0.75\left(\frac{P F}{1-P F}\right)\right)^{2}$ \\
\hline Quemada (1977) [26] & $\eta_{\mathrm{r}}=(1-P F)^{-2}$ \\
\hline
\end{tabular}

Packing fraction $(\mathrm{PF}),\left(\phi / \phi_{\mathrm{m}}\right)$, is a notation for particle packing density. It correlates to the viscosity ratio $\left(\eta_{\mathrm{r}}\right),\left(\eta_{\text {slurry }} / \eta_{\text {binder }}\right)$. Table 1 mentions some of the models. In practice, a composition that has a maximum packing fraction in CSP slurry has a maximum $\eta_{\mathrm{r}}[7,27-29]$. However, as well as in the case of DOA addition, the uncertain correlation between viscosity and particle packing density exists in nano-aluminum addition. It has been observed that the effect of nano-aluminum addition on the PF of CSP is insignificant, in contrast to its influence on viscosity [30]. Because compositions that exceed the maximum particle packing density are prone to explosion, a new criterion to determine the optimum value of particle packing density of CSP has to be defined.

Thixotropy is a proposed novel parameter intended to define particle packing density. It is a prominent characteristic in concentrated suspensions, such as cementitious materials [31-34]. Thixotropy is a property of viscosity that diminishes with time, as described in Figure 3. According to reports, factors that affect thixotropy include metal particles, chemical reactions, and plasticizers $[31,33,34]$. Because of the fast polymerization of CSP, the consequences are more complicated. Therefore, this work aims to investigate the influence of thixotropy on achieving the maximum particle packing density of CSP.

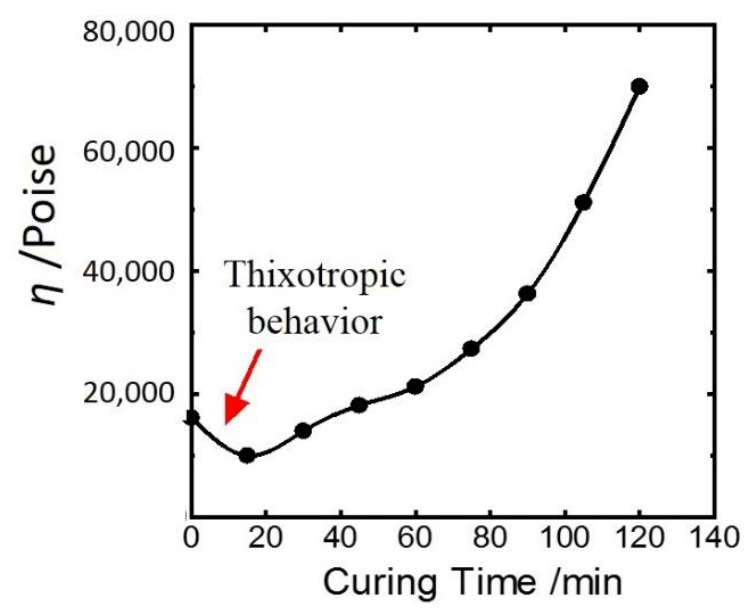

Figure 3. Thixotropy in a viscosity built-up of CSP slurry. 


\section{Materials and Methods}

Table 2 shows the composition of CSP studied in this work. All materials were produced commercially by Dalian Chlorate Co, Ltd. (Dalian, China). Hydroxyl-terminated polybutadiene (HTPB) and Toluene diisocyanate (TDI) with the weight ratio of 14:1 played a role as a polymeric matrix builder during the curing process. HTPB was manufactured from free radical polymerization, with a molecular weight of $2300-2800 \mathrm{~g} / \mathrm{mol}$, a hydroxyl value of $47.1 \mathrm{mg} \mathrm{KOH} / \mathrm{g}$, a polydispersity index of 2.5 , the density of $0.8-0.9 \mathrm{~g} / \mathrm{cm}^{3}$, and low viscosity of $40-50$ Poise at $30^{\circ} \mathrm{C}$. TDI had a high content of 2,4-TDI isomer (80.5\%), while Tepanol had a density value $=1.1 \mathrm{~g} / \mathrm{cm}^{3}$. All compositions were arranged precisely based on the ratio of $\mathrm{Al} / \mathrm{DOA}$, to produce CSP slurry with various thixotropic behavior. The following sets were also used to support that purpose. The solid content was set to be around $87.5 \%$. Ammonium perchlorate, $\mathrm{AP}_{\mathrm{f}}(50 \mu \mathrm{m})$, and $\mathrm{AP}_{\mathrm{c}}(200 \mu \mathrm{m})$ were used with a weight fraction $\left(\mathrm{AP}_{\mathrm{f}} / \mathrm{AP}_{\mathrm{c}}\right)$ of $\frac{1}{4}$. Figure 4 shows an SEM spectrogram of the aluminum $(30 \mu \mathrm{m})$ that was used in this work. It was analyzed in vacuum conditions by using Phenom Pharos Desktop SEM with a resolution of $2000 \times$.

Table 2. Composition of CSP Slurries.

\begin{tabular}{cccccc}
\hline No. & Al/DOA & $\begin{array}{c}\text { HTPB } \\
\mathbf{( \% . w t )}\end{array}$ & $\begin{array}{c}\text { TDI } \\
\mathbf{( \% . w t )}\end{array}$ & $\begin{array}{c}\text { Tepanol } \\
\mathbf{( \% . w t )}\end{array}$ & AP (\%.wt) \\
\hline 1 & 12.00 & 10.547 & 0.753 & 0.2 & 75.5 \\
\hline 2 & 12.73 & 10.547 & 0.753 & 0.1 & 73.5 \\
\hline 3 & 13.64 & 10.547 & 0.753 & 0.1 & 72.5 \\
\hline 4 & 15.89 & 10.775 & 0.77 & 0.2 & 75.5 \\
\hline 5 & 19.74 & 10.817 & 0.773 & 0.15 & 72.5 \\
\hline 6 & 23.68 & 10.817 & 0.77 & 0.15 & 69.5 \\
\hline
\end{tabular}

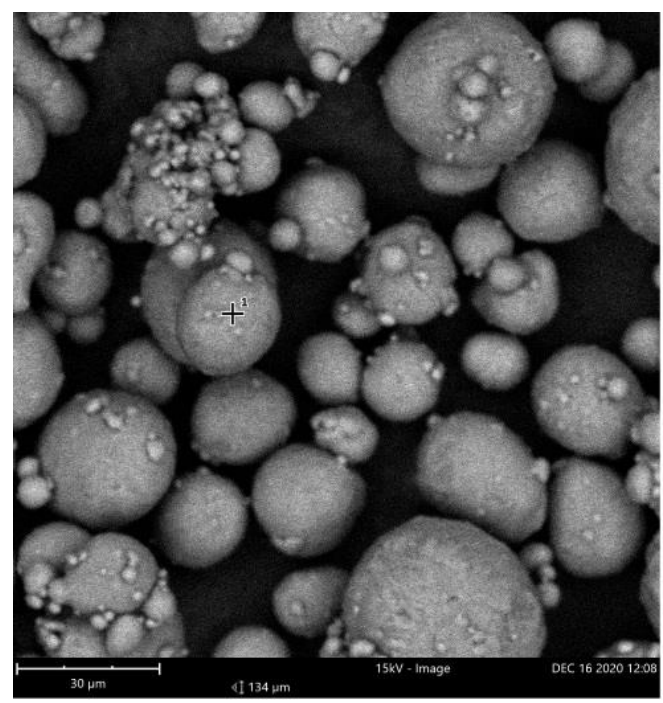

Figure 4. SEM analysis of aluminum powder.

In the mixing process, all materials were mixed in a batch system of a planetary-type mixer. Mixing specifications were set to allow for particle packing that causes defects on CSP solid, not environmental water vapor. They included using a horizontal sigma blade, vacuum equipment, the application of temperatures of $50-55{ }^{\circ} \mathrm{C}$ and a high rotational speed of $60 \mathrm{rpm}$. The mixing was divided into two parts. The first part was before the addition of TDI, while the second part was after the addition of TDI. To avoid any defects 
caused by non-uniform particle distribution, AP was divided into four parts precisely. It was introduced in sequences during the first part of mixing.

$$
\sigma=\sigma_{\mathrm{y}}+\mathrm{a} \dot{\gamma}+\mathrm{b} \dot{\gamma}^{\mathrm{c}}
$$

The rheological properties of CSP slurries were analyzed using the Rheometer Brookfield DV3T every $15 \mathrm{~min}$ at a temperature of $50{ }^{\circ} \mathrm{C}$. They included viscosity build-up, yield stress, and stress-growth. Viscosity build-up was determined to calculate the viscosity at the end of mixing $\left(\eta_{\mathrm{EOM}}\right)$ and relative viscosity $\left(\eta_{\mathrm{rel}}=\eta_{\mathrm{t} /} \eta_{\mathrm{EOM}}\right)$. For viscosity build-up and stress-growth measurement in startup shear, a low spindle speed $\left(0.01667 \mathrm{~s}^{-1}\right)$ was set, while for yield stress measurement, the shear rate of $0.01667-0.1667 \mathrm{~s}^{-1}$ was applied and plotted towards shear stress based on the Tscheuschner model, Equation (1), which is an appropriate model for CSP [35]. In Equation (1), $\dot{\gamma}$ is shear rate, $\sigma$ is shear stress and $\sigma_{\mathrm{y}}$ is yield stress.

As an attempt to investigate the physical origin of thixotropic behavior, each of the steps in stress-growth experiments were conducted by measuring shear stress $(\sigma)$ for $60 \mathrm{~s}$. A typical curve of the stress-growth experiment is presented in Figure 5, where $\sigma_{\max }$ and $\sigma_{\text {eq }}$ referred to maximum shear stress and shear stress at the equilibrium stage, respectively. To investigate the origin of thixotropic behavior, the curve was divided into two regions, elastic and plastic. The borderline of the two regions was $\sigma_{\max }$. Parameters from the elastic region were $G$ and $t_{\sigma \max }$. $G$ was a shear modulus, while $t_{\sigma \max }$ was the time needed to reach $\sigma_{\max }$. On the other hand, the parameter of the plastic region was $k_{\mathrm{fs}}$ based on the Figoni-Shoemaker model, as shown in Equation (2) [36]. In addition, the ratio of energy $(E)$ in elastic/plastic regions was calculated from the area below each curve.

$$
\sigma=\sigma_{\mathrm{eq}}+\left(\sigma_{\mathrm{max}}-\sigma_{\mathrm{eq}}\right) \exp \left(-k_{\mathrm{fs}} t\right)
$$

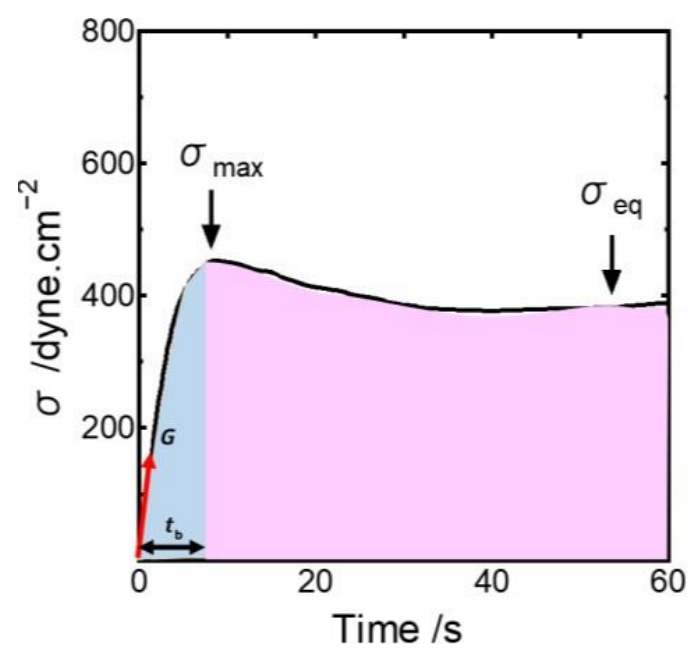

Figure 5. Stress-growth curve in start-up shear; blue area is an elastic region and pink area is a plastic region.

The process from slurry to the solid phase of CSP included casting and curing. Casting was carried out vertically. The template was cylindric with a hollow inside. On the other hand, the curing process was performed at $60{ }^{\circ} \mathrm{C}$ for 3 days. It was followed by $\mathrm{X}$-ray radiography on CSP solid using the Phillips $300 \mathrm{kV}$ CR100. It was performed to detect any defects in the structure. Bands with gradual grayscales were used as a standard according to ISO $19232 \mathrm{~J} 249$.

\section{Results and Discussion}

CSP slurry has a complex composition. It includes particles, polymers, and plasticizers. After mixing, the slurry is cast vertically. The time needed for casting is around $30 \mathrm{~min}$. In 
this work, in the viscosity measurement, the temperature of the slurry is $50{ }^{\circ} \mathrm{C}$ to resemble its temperature in the casting process. During the casting process, the slurry undergoes curing. Thus, $x$-axis in Figure 5 is called curing time.

Figure 6 shows the relative viscosity $\left(\eta_{\text {rel }}\right)$ of samples during the curing process. Relative viscosity is viscosity at a measurement time divided by viscosity at the end of mixing. It is different from $\eta_{\mathrm{r}}$ mentioned in Table 1 , which is viscosity of filled polymer divided by viscosity of the polymer. Here, thixotropic behavior refers to decreased viscosity with time. In Figure 6, it is noteworthy that all of the samples show the peak of thixotropic behavior at the 15 th minute of the curing process. The similarity could be attributed to the same composition of HTPB:TDI 14:1. In the HTPB-TDI-DOA system, it is reported that the use of the mixture 2,4-TDI and 2,6-TDI causes a lower viscosity for a longer time than the use of 2.4-TDI only [15,37]. It is because the reactivity of 2,6-TDI is lower than 2,4-TDI [38].

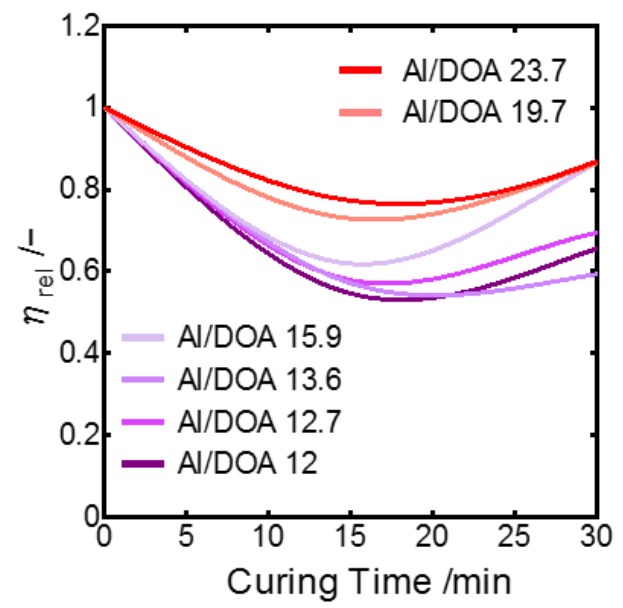

Figure 6. Various relative viscosity along curing process underlines the success of varying strengths of thixotropic behavior by varying $\mathrm{Al} / \mathrm{DOA}$.

The correlation between the $\mathrm{Al} / \mathrm{DOA}$ ratio and viscosity at the end of mixing $\left(\eta_{\mathrm{EOM}}\right)$ and at the peak time of thixotropic behavior $\left(\eta_{\min }\right)$ is presented in Figure 7 . It is shown that the correlation between composition and viscosity fluctuates. The fluctuation is also reported on cementitious materials with the presence of plasticizers [39]. The reason is explained later. Despite the fluctuation correlation, it is clearly shown that the composition that has the highest value of $\eta_{\mathrm{EOM}}$ is different from that of $\eta_{\mathrm{min}}$. The highest $\eta_{\mathrm{EOM}}$ is possessed by Al/DOA of 15.89 (CSP-4), while the highest $\eta_{\min }$ is possessed by Al/DOA of 23.68 (CSP-6). It is stated by many researchers that a composition that has a maximum particle packing density will show a maximum value of $\eta_{\mathrm{r}}[7,22-25,27,29]$. Here, as the viscosity of CSP slurry is 100-300 times higher than the viscosity of polymer (50 Poise), the value of $\eta_{\mathrm{r}}$ is assumed to be similar to $\eta_{\mathrm{EOM}}$. Thus, it is later confirmed whether maximum particle packing density is possessed by CSP-4 or CSP-6.

$\mathrm{X}$-ray radiography is an appropriate tool to analyze the structure of CSP solid [10,40]. In Figure 8, it is remarkable that the radiograph of CSP-6 (Figure 8b) has several black spots, distinguished from CSP-4, which is flawless (Figure 8a). The black spots are confirmed as void clusters by a photograph in Figure $8 \mathrm{c}$. The voids have a diameter of $1-1.5 \mathrm{~mm}$, and a cluster's width of $2 \mathrm{~cm}$. Some of the voids form a tail. It is reported that internal voids are interpreted as areas with a lack of polymer networks [10]. Regarding the location of void clusters, which are in the upper part of CSP-6 solid, CSP-6 is suspected to have more agglomerates than other compositions. As a consequence, in the vertical casting process, the vacuum force is not strong enough to draw the last part of the slurry into the template homogenously. On the other hand, with the defect, the composition of CSP-6 exceeds the maximum particle packing density. This underlines the fact that throughout the curing process, minimum viscosity $\left(\eta_{\mathrm{min}}\right)$ is a sharper parameter than $\eta_{\mathrm{EOM}}$ to define maximum 
particle packing density. In other words, thixotropic behavior in the curing process should be considered as a better parameter in an assessment of particle packing density.

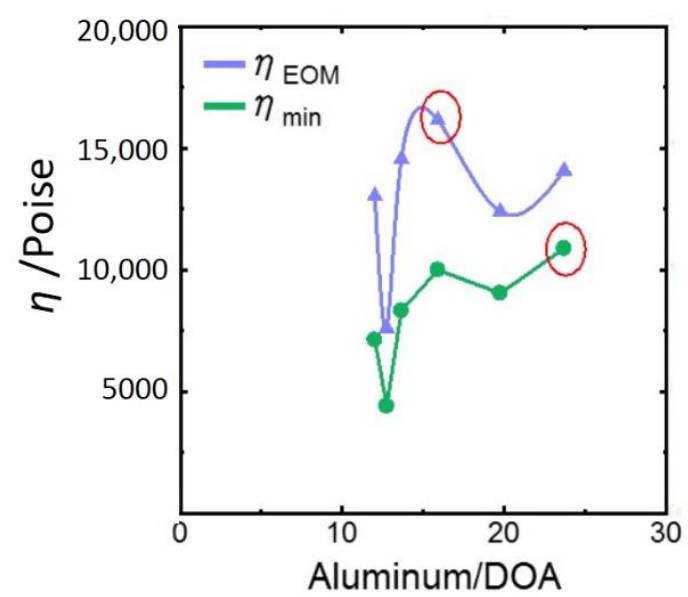

Figure 7. Maximum values of $\eta_{\mathrm{EOM}}$ and $\eta_{\min }$ are possessed by different compositions of CSP.

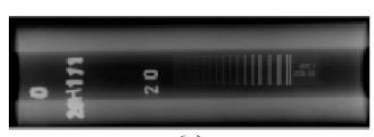

(a)

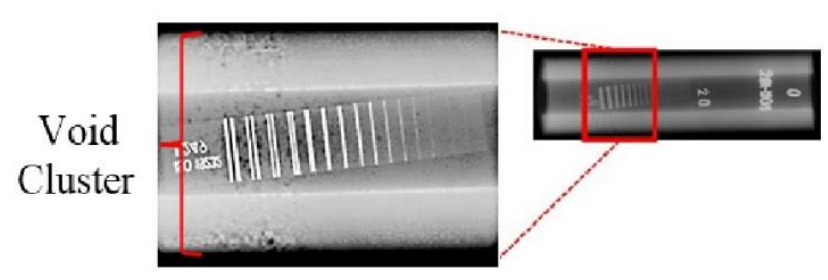

(b)
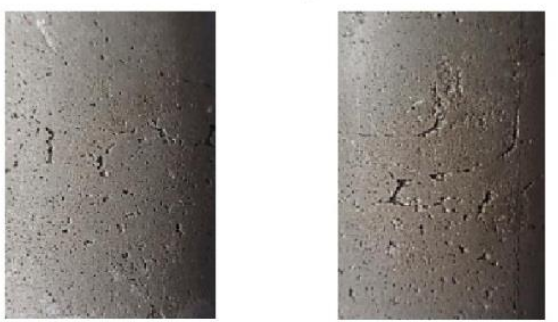

(c)

Figure 8. X-ray images of the solid of CSP-6 (b) show distinctive structure from the solid of CSP-4 (a). The defects of CSP-6 are clearly shown using an ordinary camera (c).

Figure 9 shows the apparent yield stress at the 15th minute of the curing process. The yield stress is calculated using the Tscheuschner model, as shown in Equation (1). It is observed that all CSP slurries have yield stress, as is also found by several reports for HTPBbased CSP $[20,29,41]$. A yield stress fluid is a fluid that can support its own weight to some extent. It is considered to be a sign of the presence of agglomerates [42,43]. Considering the properties of agglomerates, here, weak and strong agglomerates refer to agglomerates that are easy or difficult to be cracked or broken, respectively. Since it has been reported that stress is a function of crack [44], CSP slurry with weak agglomerates have low yield stress and vice versa. In Figure 9, remarkably, viscosity increases with an increase in yield stress. This is reasonable because viscosity describes the resistance of the fluid to flow [45] and thus, the stronger the agglomerates in the CSP slurry, the higher the viscosity [46]. The correlation brings to light that the properties of agglomerates are responsible for the fluctuating correlation between viscosity and composition, as shown in Figure 7. It is 
because the strength of inter-particle forces possessed by agglomerates is affected by many factors [47]. Effects can vary widely, even within a single agglomerate [48].

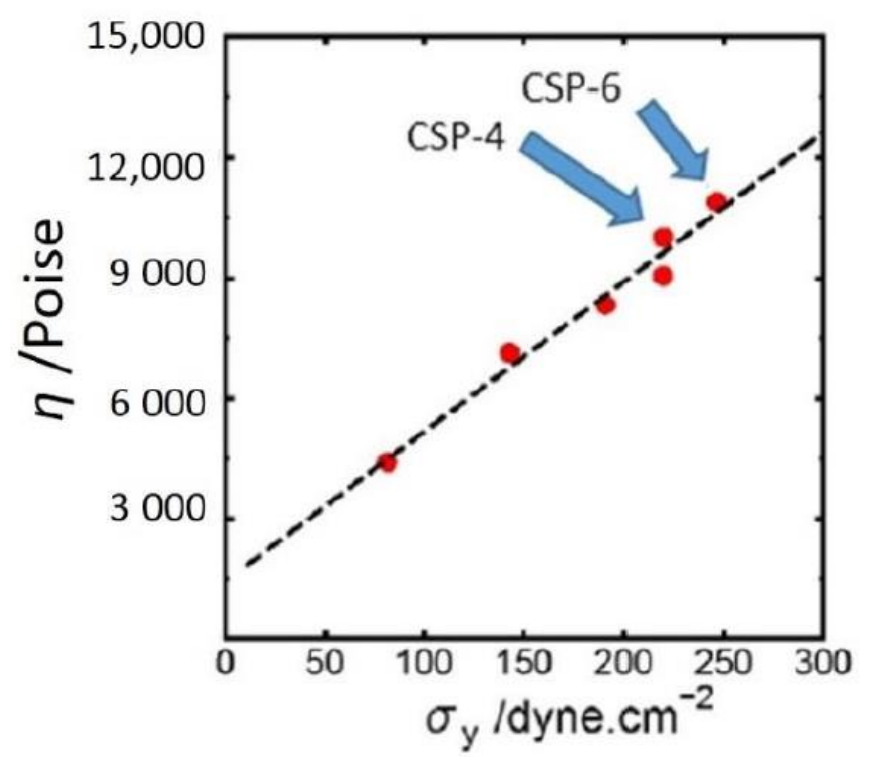

Figure 9. Viscosity dependence of CSP slurry towards yield stress emphasizes the use of agglomeration approach.

Being confirmed with X-ray radiography displayed in Figure 8, CSP-4 is found to have a composition with the maximum particle packing density. Therefore, a deep rheological analysis in start-up shear was carried out on CSP-4. Figure 10a shows the curve of stress-growth experiments towards CSP-4. The shape of the curve is similar to common highly filled materials [32,39]. It is observed that the curve shape changes over time. It is noteworthy that the curve shape at the 15th minute is extremely distinct to the curve at the initial time, while after the 15th minute, the curve shapes are similar to each other. The change in curve shape indicates energy changes. It also underlined the fact that applying a low shear rate is successfully sensitive enough to detect energy changes [46,49].

The analysis of shearing energy is shown in Figure 10b,c. There, elastic energy is required to break the structure of agglomerates, while plastic energy is required to flow the agglomerates after they have been broken [42]. Remarkably, in Figure 10b, at the 15th minute of curing, the elastic/plastic energy ratio reaches its minimum value. Figure 10c confirms that the greatest difference between elastic and plastic energy is present at the 15th minute. In Figure 10c, although both elastic and plastic energy decrease from 0 to 15 $\mathrm{min}$, the decrease in elastic energy is sharper. This means that the thixotropic behavior of CSP slurry originates more from its elastic property than its plastic property. The decrease in elastic energy indicates weakened agglomerates, which is supported by the minimum value of shear modulus, $G$, and time to reach yield stress, $t_{\sigma \max }$, in Figure $10 \mathrm{~d}$. There, $G$ is the force needed to break agglomerates, and $t_{\sigma \max }$ is the time needed to break agglomerates before flowing. Based on the shape of the elastic phase in Figure 10a in which stress-time possesses non-linear correlation, it was modeled that the mechanism of breakage involves the stretching of agglomerate structure, rather than compression [48].

In Figure $10 \mathrm{~d}$, contrary to $G$ and $t_{\sigma \max }$, the value of $k_{\mathrm{fs}}$ increases between 0 and $15 \mathrm{~min}$. Here, $k_{\mathrm{fs}}$ is calculated using the Figoni-Shoemaker model, as shown in Equation (2). The increase in $k_{\mathrm{fs}}$ continues, although with a sloping route after the 15 th minute. To figure out the phenomena, Figure 11 is presented. Figure 11 represents the relative value of shear stress $\left(\sigma_{\mathrm{t}} / \sigma_{0}\right)$ in the plastic region of CSP-4, which refers to the pink zone in Figure 5 . The level of $k_{\mathrm{fS}}$ represents how sensitive the flow of CSP slurry is towards shear stress [36]. The lower the value of $k_{\mathrm{fs}}$, the more sensitive the slurry towards stress. Here, the variety of agglomerate sizes is assumed to be the origin of the sensitivity. This is because heterogenous size of 
agglomerates has more difficulty in flowing. In this case, smaller agglomerates strongly depend on applied stress to escape through the gaps between the larger agglomerates to flow. In other words, the high $k_{\mathrm{fs}}$ indicate homogeneity of the size of agglomerates in CSP slurry after breaking. It has been reported that aluminum agglomerates in CSP have high heterogeneity in the size of which the diameter is 50-170 $\mu \mathrm{m}$ [50]. With such a wide range, it is reasonable that $k_{\mathrm{fs}}$ at $0 \mathrm{~min}$ is low, and $k_{\mathrm{fs}}$ at $15 \mathrm{~min}$ is high.

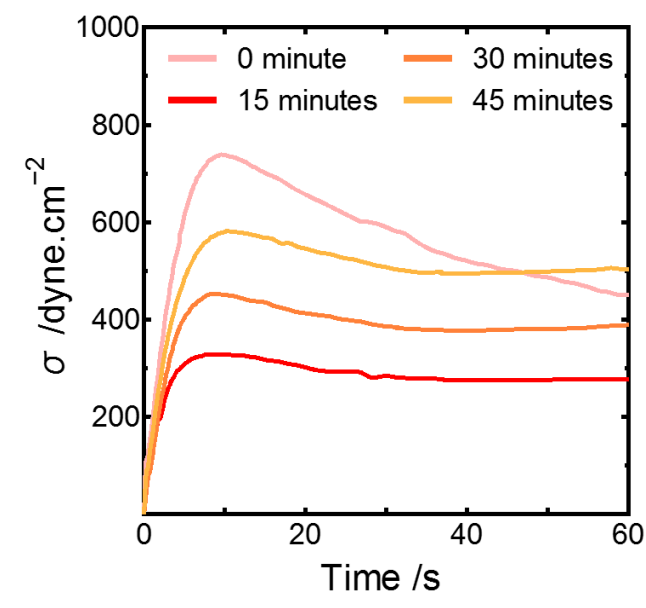

(a)

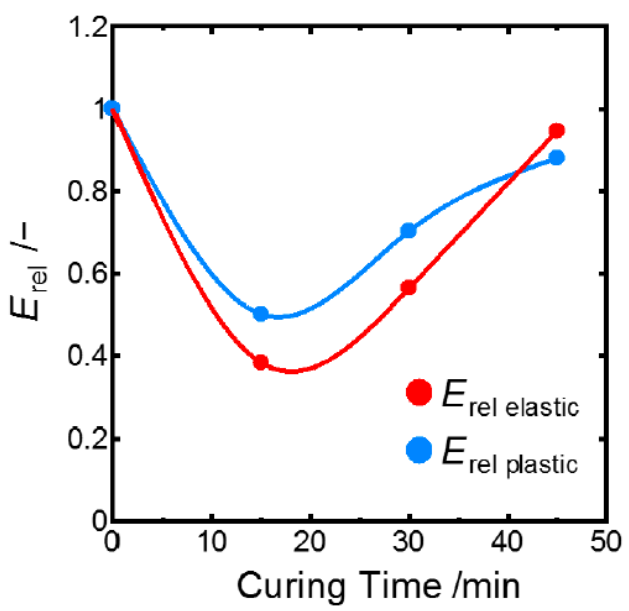

(c)

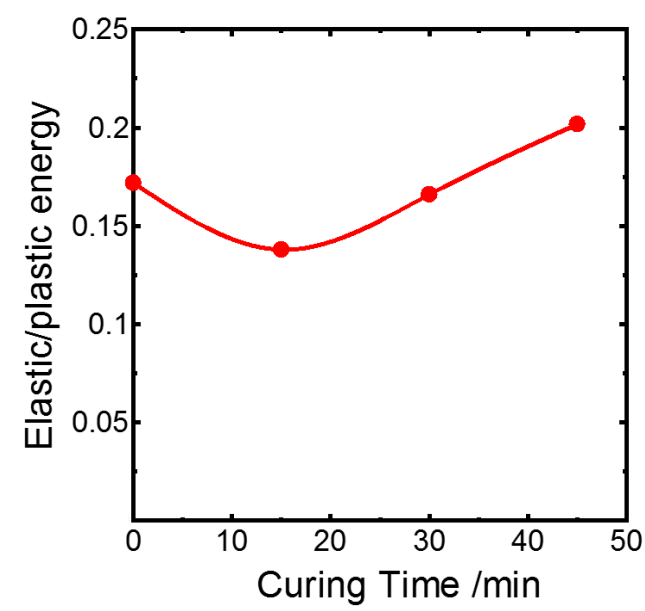

(b)

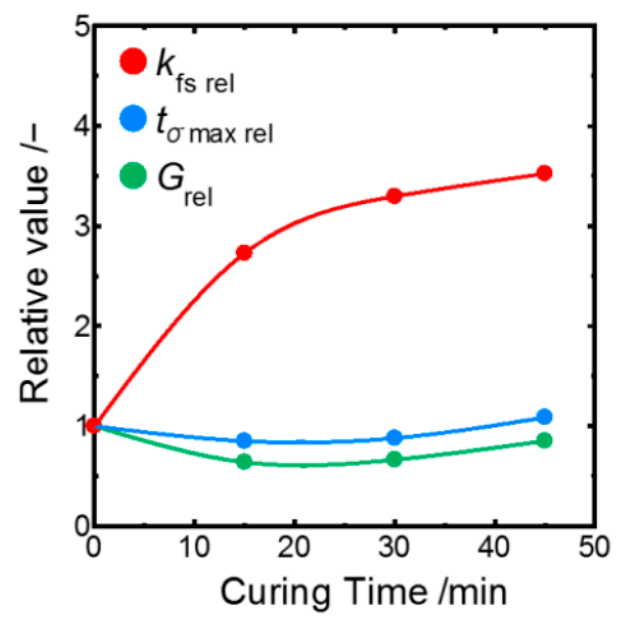

(d)

Figure 10. Stress-growth curve (a), ratio energy profile (b), elastic and plastic energy (c) and some relative values of rheological features of CSP-4 (d) during curing process underline dominancy of elastic deformation in thixotropic behavior.

According to the rheological analysis above, the suggested mechanism for the origin of thixotropic behavior during the curing process of CSP slurry is the immersion of plasticizers into agglomerates of aluminum. This is emphasized by compatibility among aluminum, HTPB, and dioctyl adipate (DOA), represented by the Hansen Solubility Parameter (HSP): the HSP of aluminum, HTPB, and DOA is $21.21,16-18.1$, and $17.6-18.2 \mathrm{MPa}^{0.5}$, respectively $[13,51,52]$. This means that aluminum is less compatible with HTPB than with DOA. This property causes aluminum particles to prefer to be close with the other aluminum particle rather than being well dispersed in HTPB-based slurry. It leads to agglomeration, as has been reported on particles with polyelectrolytes [53]. The condition is worsened by a pocket model, described in Figure 12a. According to the model, aluminum is entrapped in a space surrounded by coarse AP particles so that aluminum has difficulty in flowing [50]. On the other hand, DOA as a compatible liquid for aluminum needs time to perform perfect lubrication on aluminum because of its low weight fraction in 
CSP composition. It has been reported that when a solid is immersed in a liquid, as time elapses, liquid tends to move to free space in a structure. It occurs even in the high-density polymer [54]. Thus, with increased time, as described in Figure 12b, DOA is more absorbed into the structure of aluminum agglomerates. It is followed by lubrication, which weakens aluminum agglomerates. As the agglomerate is weakened, it is easier to be broken into a smaller agglomerate. The ability of plasticizer in breaking and modifying the size of agglomerates is proven in the field of flame-retardant materials [55], nanocomposites [56], and processing minerals [57]. The small agglomerates are aligned on the liquid to flow and it is suggested as the mechanism of plasticizer in lowering viscosity [29], described in Figure 12c. With the observed low shear modulus, the short required time to reach apparent yield stress and the less sensitivity toward shear stress, this work found that the peak of this action occurs at the 15th minute of curing time, when the polymer network is not fully built.

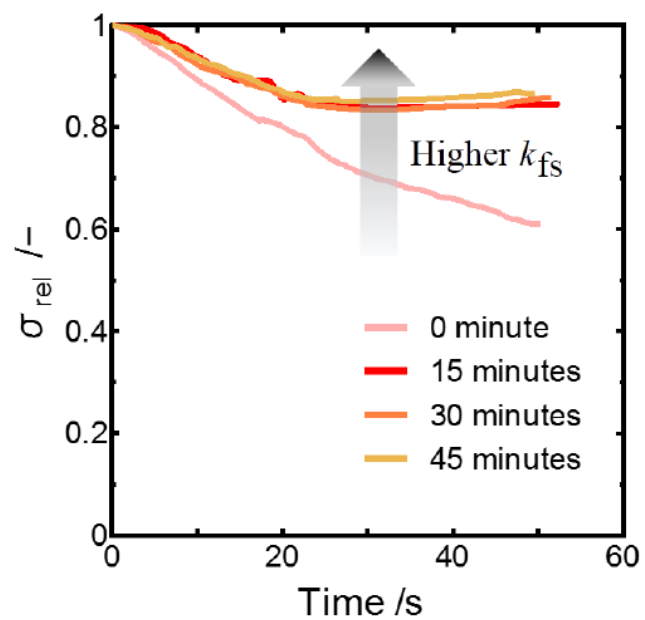

Figure 11. Relative stress in plastic region gains physical meaning of $k_{\mathrm{fs}}$.

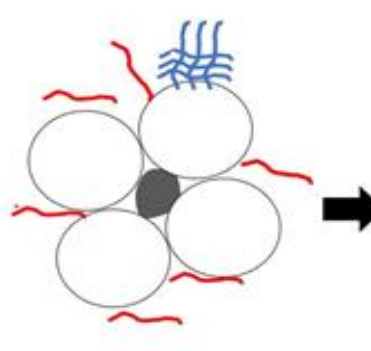

(a)

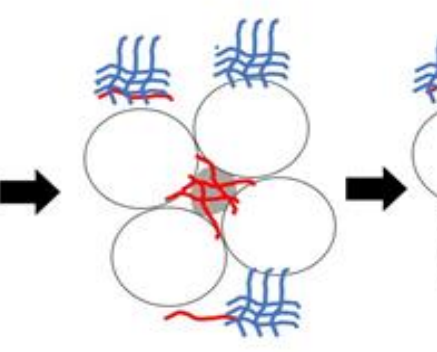

(b)

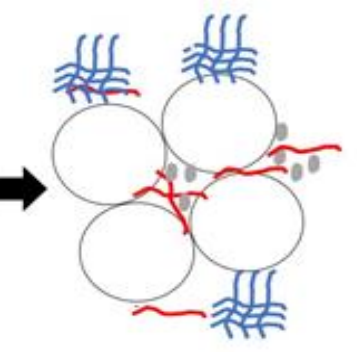

(c)

Figure 12. Mechanism of thixotropic behavior of CSP slurry; diffusion of DOA into hard Al agglomerates at $0 \mathrm{~min}$ (a), optimum lubrication of DOA and weakening of hard $\mathrm{Al}$ agglomerate at $15 \mathrm{~min}$ (b), alignment of weak $\mathrm{Al}$ agglomerates to flow (c).

\section{Conclusions}

In this work, we investigated the influence of thixotropy on the achieved maximum particle packing density of CSP. Due to its thixotropic behavior, we analyzed the timedependent viscosity of semi-cured CSP slurry. By evaluating the structural perfection of its solid phase using X-ray radiography, we show strong evidence that relative viscosity at the peak time of thixotropy, and not viscosity at the end of mixing, is an ideal parameter to define particle packing. The investigation of yield stress at the time shows the attribution of aluminum agglomerates. It is strongly affected by the elastic deformation of agglomerates. Based on compatibility, we assumed that the committed mechanisms are the weakened aluminum agglomerates because of diffusion and the lubrication of plasticizers. As a final 
word, we strongly suggest using relative viscosity at the peak time of thixotropy to evaluate the particle packing density of highly filled materials. Controlling the relative viscosities by varying the composition of CSP will be presented in our further research.

Author Contributions: Conceptualization, A.R.; methodology, A.R.; validation, A.R.; formal analysis, A.R.; investigation, A.R., L.H.A., R.A. and H.R.D.S.; resources, A.R. and R.S.B.; data curation, A.R.; writing—original draft preparation, A.R.; writing—review and editing, A.R. and L.H.A.; visualization, A.R. and H.R.D.S.; supervision, H.B.W.; project administration, K.H.; funding acquisition, H.B.W. All authors have read and agreed to the published version of the manuscript.

Funding: The authors thank the RISPRO-LPDP Competitive Research Program KEP-27/LPDP/2020 for funding the research.

Institutional Review Board Statement: Not applicable.

Informed Consent Statement: Not applicable.

Data Availability Statement: The data that support the findings of this study are available from the corresponding author, A.R., upon reasonable request.

Conflicts of Interest: The authors declare no conflict of interest.

\section{References}

1. DeLuca., L.T. Evolution of Solid Rocket Propellant Formulation for Space Propulsion. In Proceedings of the 1st Workshop on RED of Energetic Materials (RDEM); Research Center of Energetic Material Genome Science: Chengdu, China, 2016; pp. 181-196.

2. Iwasaki, A.; Matsumoto, K.; Ban, R.; Yoshihama, S.; Nakamura, T.; Habu, H. The Continuous Mixing Process of Composite Solid Propellant Slurry by an Artificial Muscle Actuator. Trans. Jpn. Soc. Aeronaut. Sp. Sci. Aerosp. Technol. Jpn. 2016, 14, 107-110. [CrossRef]

3. Mason, B.P.; Roland, C.M. Solid Propellants. Rubber Chem. Technol. 2019, 92, 1-24. [CrossRef]

4. Yadav, N.; Srivastava, P.K.; Varma, M. Recent Advances in Catalytic Combustion of AP-based Composite Solid Propellants. Def. Technol. 2021, 17, 1013-1031. [CrossRef]

5. Kakavas-Papaniaros, P.A. On The Distribution of Particles in Propellant Solids. Acta Mech. 2020, 863-875. [CrossRef]

6. Restasari, A.; Budi, R.S.; Hartaya, K. Pseudoplasticity of Propellant Slurry with Varied Aluminium Content for Castability Development. J. Phys. Conf. Ser. 2018, 1005, 012034. [CrossRef]

7. Kohga, M.; Hagihara, Y. Rheology of Concentrated AP/HTPB Suspensions Prepared at The Upper Limit of AP Content. Propellants Explos. Pyrotech. 2000, 25, 199-202. [CrossRef]

8. Abdillah, L.H.; Winardi, S.; Sumarno, S.; Nurtono, T. Effect of Mixing Time to Homogeneity of Propellant Slurry. IPTEK J. Proc. Ser. 2018, 4, 94-98. [CrossRef]

9. Dombe, G.; Jain, M.; Singh, P.P.; Radhakrishnan, K.K.; Bhattacharya, B. Pressure Casting of Composite Propellant. Indian J. Chem. Technol. 2008, 15, 420-423.

10. Hosomi, N.; Otake, K.; Uegaki, N.; Iwasaki, A.; Matsumoto, K.; Asakawa, M.R.; Habu, H.; Yamaguchi, S. Analysis of Mixed State of AP/HTPB Composite Propellant by X-ray Computed Tomography. Trans. Jpn. Soc. Aeronaut. Sp. Sci. Aerosp. Technol. Jpn. 2019, 17, 14-18. [CrossRef]

11. Vilmart, G.; Dorval, N.; Devillers, R.; Fabignon, Y.; Attal-Trétout, B.; Bresson, A. Imaging Aluminum Particles in Solid-Propellant Flames Using $5 \mathrm{kHz}$ LIF of Al Atoms. Materials 2019, 12, 2421. [CrossRef]

12. Singh, A.; Radhakrishnan, S.; Vijayalakshmi, R.; Talawar, M.B.; Kumar, A.; Kumar, D. Screening of Polymer-Plasticizer Systems for Propellant Binder Applications: An Experimental and Simulation Approach. J. Energ. Mater. 2019, 37, 365-377. [CrossRef]

13. Wypych, G. Handbook of Plasticizers, 3rd ed.; ChemTec Publishing: Toronto, ON, Cananda, 2017. [CrossRef]

14. Restasari, A.; Abdillah, L.H.; Ardianingsih, R.; Wicaksono, B.; Budi, R.S. The Compatibility of Model for Low Shear Flow Analysis in Developing Plasticized Htpb-Based Binder. Spektra J. Fis. Dan Apl. 2020, 5, 189-200. [CrossRef]

15. Golofit, T.; Ganczyk-Specjalska, K.; Jamroga, K.; Kufel, L. Rheological and Thermal Properties of Mixtures of Hydroxyl-Terminated Polybutadiene and Plasticizer. Polimery 2018, 63, 53-63. [CrossRef]

16. Restasari, A.; Abdillah, L.H.; Budi, R.S.; Hartaya, K. Pengaruh Dioctyl Adipate Terhadap Sifat Rheologi HTPB Terplastisasi. J. Teknol. Dirgant. 2018, 16, 139-149. [CrossRef]

17. Bandgar, B.M.; Krishnamurthy, V.N.; Mukundan, T.; Sharma, K.C. Mathematical Modeling of Rheological Properties of HydroxylTerminated Polybutadiene Binder and Dioctyl Adipate Plasticizer. J. Appl. Polym. Sci. 2002, 85, 1002-1007. [CrossRef]

18. Restasari, A.; Abdillah, L.H. Pengaruh Dioctyl Adipate Terhadap Pot-Life Proopelan Berformula AP Trimoda. In Proceedings of the Prosiding SIPTEKGAN XXI; Pusat Teknologi Penerbangan, LAPAN: Tangerang, Indonesia, 2017; pp. 314-322.

19. Rueda, M.M.; Auscher, M.C.; Fulchiron, R.; Périé, T.; Martin, G.; Sonntag, P.; Cassagnau, P. Rheology and Applications of Highly Filled Polymers: A Review of Current Understanding. Prog. Polym. Sci. 2017, 66, 22-53. [CrossRef] 
20. Dombe, G.; Yadav, N.K.; Lagade, R.M.; Bhongale, C. Studies on Measurement of Yield Stress of Propellant Suspensions Using Forced Falling Ball and Slump Test. Appl. Rheol. 2017, 27, 1-7. [CrossRef]

21. Koutný, O.Ĝ.; Kratochvíl, J.Ĝ.; Švec, J.Ĝ.; Bednárek, J. Modelling of Packing Density for Particle Composites Design. In Proceedings of the Procedia Engineering; Elsevier: Brno, Czech Republic, 2016; Volume 151, pp. 198-205. [CrossRef]

22. Eilers, H. Die Viskositäts-Konzentrationsabhängigkeit Kolloider Systeme in Organischen Lösungsmitteln. Kolloid Z 1943, 102, 154-169. [CrossRef]

23. Mooney, M. The Viscosity of a Concentrated Suspension of Spherical Particles. J. Colloid Sci. 1951, 6, 161-170. [CrossRef]

24. Krieger, I.; Dougherty, T. Mechanism for Non-Newtonian Flow in Suspensions of Rigid Spheres. Trans. Soc. Rheol. 1959, 3, 137-152. [CrossRef]

25. Chong, J.; Christiansen, E.; Baer, A. Rheology of Concentrated Suspensions. J. Appl. Polym. Sci. 1971, 15, 2007-2021. [CrossRef]

26. Quemada, D. Rheology of Concentrated Disperse Systems and Minimum Energy Dissipation Principle. Rheol. Acta. 1977, 16, 82-94. [CrossRef]

27. Erisken, C.; Gocmez, A.; Yilmazer, U.; Pekel, F.; Ozkar, S. Modeling and Rheology of HTPB Based Composite Solid Propellants. Polym. Compos. 1998, 19, 463-472. [CrossRef]

28. Sweeney, K.H.; Geckler, R.D. The Rheology of Suspensions. J. Appl. Phys. 1954, 1135, 1954. [CrossRef]

29. Muthiah, R.; Krishnamurthy, V.N.; Gupta, B.R. Rheology of HTPB Propellant. 1. Effect of Solid Loading, Oxidizer Particle Size, and Aluminum Content. J. Appl. Polym. Sci. 1992, 44, 2043-2052. [CrossRef]

30. Lade, R.; Wasewar, K.; Sangtyani, R.; Kumar, A. Effect of Aluminum Nanoparticles on Rheological Behavior of HTPB-Based Composite Rocket Propellant. J. Energ. Mater. 2018, 37, 125-140. [CrossRef]

31. Cesar, R.; Romano, D.O.; Rebmann, M.S.; Montefusco, H.; Raucci, J.; Massucato, C.; Pileggi, R.G. Impact of Particle Packing on The Rheological Properties of Cementitious Pastes Dispersed with Polycarboxylate. Annu. Trans. Nord. Rheol. Soc. 2017, 25, 398-404.

32. Mahaut, F.; Mokéddem, S.; Chateau, X.; Roussel, N.; Ovarlez, G. Effect of Coarse Particle Volume Fraction on The Yield Stress and Thixotropy of Cementitious Materials. Cem. Concr. Res. 2008, 38, 1276-1285. [CrossRef]

33. Mbasha, W.; Masalova, I.; Haldenwang, R.; Malkin, A. The Yield Stress of Cement Pastes as Obtained by Different Rheological Approaches. Appl. Rheol. 2015, 25, 53517. [CrossRef]

34. Ojeda-Farías, O.; Hebraud, P.; Lootens, D.; Liard, M.; Mendoza-Rangel, J.M. Thixotropy of Reactive Suspensions: The Case of Cementitious Materials. Constr. Build. Mater. 2019, 212, 121-129. [CrossRef]

35. Jain, M.; Singh, D.; Balasubramanian, K.; Singh, P.P.; Bhattacharya, B.; Advanced, H.S. Studies on Prediction of Rheological Behaviour of Composite Propellant Formulations Based on Rheological Models. Adv. Sci. Eng. Med. 2015, 7, 690-696. [CrossRef]

36. Kubo, M.T.K.; Rojas, M.L.; Miano, A.C.; Augusto, P.E.D. Rheological Properties of Tomato Products. In Tomato Chemistry, Industrial Processing and Product Development; Porretta, S., Ed.; Royal Society of Chemistry: Croydon, UK, 2019; p. 2019. [CrossRef]

37. Bandgar, B.M.; Sharma, K.C.; Mukundan, T.; Krishnamurthy, V.N. Rheokinetic Modeling of HTPB-TDI and HTPB-DOA-TDI Systems. J. Appl. Polym. Sci. 2003, 89, 1331-1335. [CrossRef]

38. Szycher, M. Szycher's Handbook of Polyurethanes; CRC Press: Boca Raton, FL, USA, 2013. [CrossRef]

39. Roussel, N.; Bessaies-Bey, H.; Kawashima, S.; Marchon, D.; Vasilic, K.; Wolfs, R. Recent Advances on Yield Stress and Elasticity of Fresh Cement-based Materials. Cem. Concr. Res. 2019, 124, 105798. [CrossRef]

40. Florczak, B.; Białek, M.; Cholewiak, A. Determination of the Internal Ballistic Properties of Solid Heterogeneous Rocket Propellants. Cent. Eur. J. Energ. Mater. 2014, 11, 589-601.

41. Florczak, B.; Bednarczyk, E.; Maranda, A. Studies of Rheological Properties of Suspension of Heterogeneous Rocket Propellant Based on HTPB Rubber. CHEMIK 2015, 69, 136-145.

42. Osman, M.A.; Atallah, A.; Schweizer, T.; Öttinger, H.C. Particle-Particle and Particle-Matrix Interactions in Calcite Filled High-Density Polyethylene-Steady Shear. J. Rheol. 2004, 48, 1167-1184. [CrossRef]

43. Roussel, N. Rheology of Fresh Concrete : From Measurements to Predictions of Casting Processes. Mater. Struct. 2007, 40, 1001-1012. [CrossRef]

44. Griffith, A.A. The Phenomena of Rupture and Flow in Solids. Philos. Trans. R. Soc. A 1921, 221, 582-593. [CrossRef]

45. Metzner, A.B. Rheology of Suspensions in Polymeric Liquids. J. Rheol. 1985, 29, 739-775. [CrossRef]

46. Bouillard, J.; Henry, F.; Marchal, P. Rheology of Powders and Nanopowders Through The Use of A Couette Four-Bladed Vane Rheometer: Flowability, Cohesion Energy, Agglomerates and Dustiness. J. Nanoparticle Res. 2014, 16, 2558. [CrossRef]

47. Llusa, M.; Levin, M.; Snee, R.D.; Muzzio, F.J. Shear-Induced APAP De-agglomeration. Drug Dev. Ind. Pharm. 2009, 35, 1487-1495. [CrossRef]

48. Bika, D.G.; Gentzler, M.; Michaels, J.N. Mechanical Properties of Agglomerates. Powder Technol. 2001, 117, 98-112. [CrossRef]

49. Dai, C.; Wu, A.; Qi, Y.; Chen, Z.; Li, B. Mechanical Properties of Paste Slurry under Constant Shear Rate in Initial Structure Failure Process. Adv. Mater. Sci. Eng. 2019, 2019, 2971563. [CrossRef]

50. Gallier, S. A Stochastic Pocket Model for Aluminum Agglomeration in Solid Propellants. Propellants Explos. Pyrotech. 2009, 34, 97-105. [CrossRef]

51. Hansen, C.M. Polymer Additives and Solubility Parameters. Prog. Org. Coat. 2004, 51, 109-112. [CrossRef]

52. Ruellan, A.; Guinault, A.; Sollogoub, C.; Ducruet, V.; Domenek, S. Solubility Factors as Screening Tools of Biodegradable Toughening Agents of Polylactide. J. Appl. Polym. Sci. 2015, 132, 42476. [CrossRef] 
53. Mori, T.; Hori, Y.; Fei, H.; Inamine, I.; Asai, K.; Kiguchi, T.; Tsubaki, J. Experimental Study About the Agglomeration Behavior in Slurry Prepared by Adding Excess Polyelectrolyte Dispersant. Adv. Powder Technol. 2012, 23, 661-666. [CrossRef]

54. Ito, A.; Hioki, K.; Kono, K.; Hiejima, Y.; Nitta, K. Effects of Liquid Paraffin on Dynamic Mechanical Properties of Linear High-Density Polyethylene. Macromolecules 2020, 53, 8459-8466. [CrossRef]

55. Xu, J.L.; Lin, Y.G.; Yang, W.L.; Kang, C.H.; Niu, L. Application of Nanometer Antimony Trioxide Modified by Dioctyl Phthalate in Polyvinyl Chloride Flame Retardant Materials. Mater. Res. 2020, 23, 1-10. [CrossRef]

56. Bohn, S.; Balzer, P.S.; Becker, D. Role of Plasticizer and Dispersion Methods on The Properties of Poly(vinyl chloride) and Clay Nanocomposites. J. Vinyl Addit. Technol. 2018, 24, E172-E176. [CrossRef]

57. Polowczyk, I.; Szubert, A.; Sadowski, Z.; Jażdżyk, E. Effect of Polymer-Surfactant Interaction onto The Spherical Agglomeration. Physicochem. Probl. Miner. Process. 2004, 38, 351-358. 